\title{
The Binary Opposition of Structure and mobility in Debates: A Discussion on Structure and mobility in Anthropology Theory
}

\author{
Gou Aiping \\ Art History, Department of Xi'an Academy of Fine Arts, Shaanxi, China, 710065
}

Keywords: structure, mobility, debates, binary opposition

Abstract: Before 1980s, there were mainly two perspectives in the discussion of the relationship between society and individuals. The first one emphasizes a structural study on entirety, and the second one focuses on the study of individual mobility. After 1980s, the emergence of practice theory broke up the opposite status of structure and mobility. Practice theory tends to take the middle route and establish balance between structure and mobility. The above theories are different because of their different research angles. All these theories are reasonable, and they have enriched and promoted the development of theoretical paradigm of anthropology.

In anthropology theories, the discussion of the relationship between society and individuals can be divided into two paradigms: structure tendency and mobility tendency. Prior to1960s, the case is often that one particular theory dominated over a period of time, thus giving rise to different schools of anthropology. After the 1960s, the theoretical paradigm became complex and diverse, and the controversy focused on the two opposites between structure and mobility.

\section{Theoretical schools with structure tendency}

Generally speaking, structural theorists argue that social structure determines a society, denying individual mobility and emphasizing individual action as a product of the whole social structure.

\subsection{French Anmales School}

Durkheim (Émile Durkheim) is the successor of Positivism by Comte (Isidore Marie Auguste François Xavier Comte). He believed that explaining social phenomena required the use of social facts, such as morality, law, religious beliefs, rituals, art, customs and so on. "The two characteristics of social fact lie in its externality and compulsion, that is, its existence precedes any individual and restricts and dominates individual behavior, but can not promote creativity and mobility. Social phenomena, as distinct from physiological and psychological phenomena, can only be explained according to social facts, their composition and the mechanism of maintaining society." Durkheim pointed out that society has integrity and can not use personal psychological thinking to study the whole society. Social phenomena need to be explained by social facts. Durkheim's concepts of collective image and collective consciousness have a wide and far-reaching 
influence on later theories.

\subsection{Radcliffe Brown's Structural-Function theory}

Radcliffe-Brown's theory integrates individuals into the system of social groups. Individuals are all dependent on social organizations. He believes that structure is the personnel arrangement in society. Brown's concern is how society is formed into an effective whole. He believes that social forms are cultural systems, values, rituals and so on. Brown believes that "social structure refers to the relationship between people in a cultural unity. The relationship between people is governed by the system. The content of human social structure is the individual of society, and its form is system." Brown put forward that social structure determines social form in his theory, and his theory also had a great influence on Anthropology later.

\subsection{Levi-Strauss and structuralism}

Brown and Levi-Strauss both use the word "structure", but they do differ substantially in their understanding and interpretation of the structure. Levi Strauss studied not the entity structure, but the thinking structure.In Levi-Strauss's view, human beings are in different cultures, and the cultural image or appearance is different. However, he also believes that although cultural images are different, the thinking structure behind cultural images is consistent. The basis of consistency is the irrational unconscious structure of human binary opposition mode. Conscious structure is not real structure. Unconscious structure is hidden in the depths of the human mind, it is difficult to be directly perceived. The task of the researcher is to find the unconscious structure, the mental structure, which exists in the depths of the human mind, and to understand social relations.

\subsection{Max Gluckman's Theory}

Max Gluckman think "The balance of social structure is neither static nor stable, but results from an ongoing dialectical process. There are conflicting values, principles and interests in society. Society does not balance directly and skillfully through integration, but through the effective absorption of various conflicting factors and conflicts." In his study of Swazi Enkovala rituals, he pointed out that the rebellion rituals are a kind of ritual conducive to decompression, through decompression to ease social conflicts, and ultimately promote social solidarity to a certain extent. On the whole, he still emphasizes the stability of the overall structure, so his theory has not been able to effectively explain the problem of social change.

\subsection{Turner and Douglas's Theory}

Victor Turner and Mary Douglas are representatives of symbolic anthropology. They mainly study symbolic symbols, and they are all influenced by Durkheim and structure-function school. Although the starting point of the study is different, but generally speaking, the two studies discuss the social structure and symbolic symbols under the background of social consensus, and emphasize that the social structure and symbolic symbols should be equated. Turner's research focuses on how symbolic rituals balance social conflicts, while Douglas focuses on the correspondence between symbols and social structures.

The above-mentioned theoretical schools which take structure as the object of study, generally regard society as a whole to study, do not pay attention to the the active effect human beings have on the structure, ignoring the decisive role of human beings and the existence of value. 


\section{Theories Concerning Individual Needs and Mobility}

Since the 1950s, scholars have begun to break away from the previous singular focus on structural research, and anthropological research has begun to turn to focus on the dynamic role of human beings.

\subsection{Malinowski's theory of demand-function}

Strictly speaking, Malinowski's functional theory of demand is still a cultural functional structure. However, Malinowski's demand function theory also pays close attention to personal physiological and psychological needs. dMalinowski pointed out that culture should meet the basic needs of human beings, and secondary needs are a kind of derivative needs. Only when people are satisfied with basic needs, can they further consider secondary needs. "Culture is utilitarian, adaptable and integrated. The basic function of culture is to meet people's physiological, psychological and individual social needs. "Malinowski believes that we can not analyze social culture without considering physical and psychological conditions and every aspect of life. Malinowski is not actually doing research on mobility, but in his research, individual needs are the focus of the study.

\subsection{Edmund Leach's theory of process}

Edmund Leach pointed out that people make subjective choices in favor of themselves in the face of various interests. There is no cultural norm in society, and cultural norms are idealized. Leach pointed out why there are various conflicts between people in society. This is because people are ambitious, or enterprising. People's pursuit of power is the cause of tension and conflict. Therefore, man is a major force in promoting social change. Leach believes that people have the right of choice and domination and function as actors with strong subjective mobility, who can balance changes in interests and take different actions, no longer bound to social structure. Leach believes that social balance is a dynamic balance. Society has always been in a state of change and individual action can play a role in shaping the social structure. However, some of Leach's theoretical research is still not completely divorced from the influence of structural theory, displaying more or less sense of structuralism.

\subsection{Frederick Barth's theory of transaction-action}

Leach's research makes anthropology research move from structural research to mobility research, and Frederick Barth goes deeper into the study of mobility. Barth distinguishes actions and believes that behavior and action are different. Action is subjective and behavior is objective. Action emphasizes motivation and behavior emphasizes results. Barth's theory and Brown's structural functionalism are the two opposite theories. Barth said, "People may overhead and sway the collective behavior at will. Individual interests lead to behaviors that are not conducive to collective interests. Individuals can make plans and choices according to their own interests and political interests." Because man himself is a strategic animal. In front of any choice, man will carry out a variety of calculations, will consider and optimize their own advantages and disadvantages, so as to determine their own way of action and make the appropriate choice of behavior. In his study of "Political Leadership among Swat Pathans", Barth emphasized the role of individual mobility.

These theories, which focus on individual needs and activeness, emphasize the active role of human beings in social structure and see the positive or negative impact of human beings on society. 


\section{The balance of the debate between structure and activeness in practice theory}

In the decades of theoretical research and debates among various schools, although no one has convinced the other, but on this issue has made different expositions and explanations, put forward their own views. The controversy between structure and mobility in anthropology presents a long period of binary opposition, while the new practical theory after 1980 s reconcile the binary opposition between structure and mobility.

Pierre Bourdieu was the initiator of the theory of practice, which tried to find a point of harmony between structure and mobility. Bourdieu argues that the social structure and mental structure of structural theory overemphasize the decisive role of society. When individuals break the rules or do not obey the rules of the game, the theoretical explanation of structural theory ignores the existence of these problems, Therefore, there are limitations. Bourdieu drew lessons from the theoretical studies of Weber, Marx and Levi-Strauss, trying to find a balance between structure and mobility. Practice has become the bridge and link between structure and activeness. Bourdieu balanced mobility and structure research successfully through practice theory. The theory of practice successfully connects the structure with the mobility, and balances, harmonizes and supplements the structure and the mobility.

Although the debate between structure and mobility has existed for a long time, they are not two incompatible theoretical paradigms. In the controversy over the binary opposition between structure and mobility, theories have been enriched and new theoretical paradigms have emerged. The controversy between the two represents the development, progress and openness of anthropological theory. The anthropological theory in the debate gives more space for anthropological theory.

\section{References}

[1] E.Durkheim, Les formes élementaires de la vie religieuse,translated by Lin Zongjin .[M], Beijing: Minzu University of China Press, 2002, PP. 5-11.

[2] Xia Jianzhong: Theory of Cultural Anthropology. [M], Beijing: Renmin University of China Press, 1997, p.119.

[3] Pan Jiao: Outline of Contemporary Anthropological theory, Internal Information, p.6.

[4] Malinowski, Scientific Cultural Theory, translated by Huang Jianbo etc. [M], Beijing: Minzu University of China Press, 1999, PP. 74-119.

[5] Barth, Political Leadership among Swat Pathans, translated by Huang Jiansheng. [M], Shanghai: Shanghai People's Publishing House, 2005, P. 2.

[6] Malcolm Waters, Modern Sociological Theory, Translated by Yang Shanhua and Li Kang [M], Beijing: China Press, 2004, PP. 12-13.

[7] Zhou Yi, Unscramble Society: A Path to Culture and Structure, Beijing: Social Sciences Literature Press, 2004, P. 3. [8] Huang Shuping, Gong Peihua. Research on the Theoretical Methods of Cultural Anthropology. [M], Guangzhou: Guangdong Higher Education Press, 1996, P. 365.

[9] Pierre Bourdieu, Outline of a Theory of Practice,[M],Cambridge University Press, 1977, p.72.

[10] Pierre Bourdieu, Social Use of Science, translated by Liu Chengfu, Zhang Yanyi,[M], Nanjing: Nanjing University Press, 2005, P. 30. 